\title{
New Control Strategy for a Hybrid Ground Source Heat Pump System cou- pled to a Closed Circuit Cooling Tower
}

\section{Zoi Sagia ${ }^{1 *}$ and Constantinos Rakopoulos ${ }^{2}$}

${ }^{1}$ Laboratory of Thermal Processes, Department of Thermal Engineering, School of Mechanical Engineering, National Technical University of Athens, Greece ${ }^{2}$ Laboratory of Internal Combustion Engines, Department of Thermal Engineering, School of Mechanical Engineering, National Technical University of Athens, Greece

\begin{abstract}
Hybrid Ground Source Heat Pump Systems (HGSHPSs) which include cooling towers are widely used so as to improve Ground Source Heat Pump Systems (GSHPSs) efficiency in cooling dominated applications. A Greek office building with total cooled area $1000 \mathrm{~m}^{2}$ is examined. The whole system is modelled using TRNSYS 17. System's operation is optimized using TRNOPT 17 so as to meet the maximum cooling load during the net cooling period, when no heating loads occur, by minimizing Ground Heat Exchangers (GHEs) depth. Three control strategies, based on continuous observation of critical temperatures, are applied to the optimized system. Each strategy attempts to achieve a further optimization of HGSHPS's operation by minimizing the electric power consumption. In the first one, the cooling tower is turned on when the difference between the fluid temperature exiting heat pumps and ambient air wet bulb temperature exceeds $10^{\circ} \mathrm{C}$. In the second one, the cooling tower is on when the fluid temperature exiting GHEs is greater than $28^{\circ} \mathrm{C}$. In the third one, the cooling tower starts to operate when the fluid temperature exiting heat pumps is greater than $32^{\circ} \mathrm{C}$. Each of these control points is normalized by the fluid temperature exiting the hot side of Heat Exchanger which comes in between the ground loop and the Closed Circuit Cooling Tower loop. The new set points define three new control strategies which are examined so as to achieve a further improvement to HGSHPS's operation.
\end{abstract}

Keywords: Hybrid ground source heat pump system; Ground heat exchanger; Closed circuit cooling tower; Heat pump; Control strategy

\section{Introduction}

The use of Hybrid Ground Source Heat Pump Systems (HGSHPSs) has become very popular, nowadays. This happens due to the fact that HGSHPSs achieve a better energy saving performance than conventional Ground Source Heat Pump Systems (GSHPSs), thanks to supplemental heat rejection or extraction subsystems.

In the current work a HGSHPS which is coupled with a Heat Exchanger loop and a Closed Circuit Cooling Tower loop is examined. The studied HGSHPS is applied to a Greek office building with total cooled area $1000 \mathrm{~m}^{2}$ and accounts for a cooling dominated climate. Different control strategies are applied to cooling tower's operation so as to minimize the whole system's electric power consumption during the net cooling period or in other words the period when only cooling loads occur.

Various studies have been done so as to propose control methods which lead to a more efficient operation of cooling towers in HGSHPSs. Kavanaugh [1] revises the HGSHPS sizing which has been proposed in ASHRAE [2] and suggests a balancing method so as to make up for the heat pump lessening performance due to the ground temperature increase in the borehole field. He concludes that the use of HGSHPSs is more energy and money saving in warm and hot climates than in moderate ones. Yavutzurk and Spitler [3] perform a comparative study of different operating and control strategies of a HGSHPS using an hourly short time step simulation. This system includes a mechanical draft, open circuit cooling tower which is coupled with the ground loop by a plate heat exchanger. The best strategy is the one which activates the cooling tower fan when the temperature difference between the fluid exiting the heat pump and the ambient air wet bulb temperature is greater than a set point, which could be increased and it is depended on system's operating characteristics and climate. However, the control strategy with the least operating hours per year is not necessarily the most cost effective one. $\mathrm{Xu}$ [4] proposes three control strategies. The first one determines set point at which the cooling tower starts its operation according to the temperature difference across the heat pump. The second one is a forecast/historical control strategy which depends on the ability to estimate the possible loads and energy savings of the heat pumps. The third one is based on linear functions of entering and exiting fluid temperatures of the heat pump with the average loop temperature deviation. All of them have satisfactory energy saving percentage to the studied HGSHPSs without the need of separate optimization of each system. Hackel et al. [5] developed design guidelines for hybrid cooling and heating dominated systems. The cooling dominated HGSHPS includes a closed circuit cooling tower which is coupled with the heat pump system without the presence of heat exchanger. The optimal control set point for this tower is when the fluid temperature entering it is greater than the ambient wet bulb temperature plus a temperature difference which is chosen according the ASHRAE $1 \%$ design wet bulb temperature for the building's climate in July.

\section{HGSHPS Modelling}

\section{Building modelling}

In the present article, a mainly glass office building with total cooled area $1000 \mathrm{~m}^{2}$ is the case study. It bears insulating, Ar, 4/16/4

*Corresponding author: Dr. Zoi Sagia, Department of Thermal Engineering School of Mechanical Engineering, National Technical University of Athens, Greece, Email: zoisagia@mail.ntua.gr

Received April 11, 2012; Accepted May 02, 2012; Published May 04, 2012

Citation: Sagia Z, Rakopoulos C (2012) New Control Strategy for a Hybrid Ground Source Heat Pump System coupled to a Closed Circuit Cooling Tower. J Appl Mech Eng 1:108. doi:10.4172/2168-9873.1000108

Copyright: (c) 2012 Sagia Z, et al. This is an open-access article distributed under the terms of the Creative Commons Attribution License, which permits unrestricted use, distribution, and reproduction in any medium, provided the original author and source are credited. 
glazing with thermal transmittance $u=1.4 \mathrm{~W} / \mathrm{m}^{2} \mathrm{~K}$ and solar heat gain coefficient $g=0.589$.

The climatic data referred to Athens city and have been derived from Meteonorm 6.1 [6] in the form of Typical Meteorological Year TMY 3.

The cooled area of the building is modelled as one thermal zone in which the set point cooling temperature is $26^{\circ} \mathrm{C}$ with $45 \%$ air humidity according to new, Greek legislation on buildings [7] applied on January 2011.

The whole system is modelled using TRNSYS 17 [8]. However, two different .tpf files have been built so as to perform the simulation by decreasing the demanded computational time. The first one determines the building loads and the second one simulates the HGSHPS's operation. The cooling load output of the first file is used to create an Excel file which is read by the second .tpf file. The distribution cooling system to the building is not examined.

Figure 1 shows the annual building load profile. It is very obvious that the annual cooling loads are much higher than the heating ones and this leads to a cooling dominated system. The annual cooling demand is $105.79 \mathrm{kWh} / \mathrm{m}^{2}$ and the total cooling demand for the period of interest in this work, which is the net cooling period when only cooling loads exist in the building, is $74 \mathrm{kWh} / \mathrm{m}^{2}$ ( $70 \%$ of the annual load). This period is running through June to September and it is defined in figurel between the dashed lines. The peak cooling load is $70.3 \mathrm{~kW}$.

\section{HGSHPS modelling}

As it has been mentioned in Section 4.1 the HGSHPS is modelled in a separate .tpf file which includes useful TESS components [9]. Figure 2 depicts a schematic diagram of simulation. The system is divided into three main loops which are depicted in different colours: the Ground Heat Exchangers' (GHEs') loop coupled with the heat pumps in blue, the Heat Exchanger loop which comes in between the GHEs' loop and the Closed Circuit Cooling Tower loop in green and the Closed Circuit Cooling Tower loop in cyan blue.

The main parts of HGSHPS are: the GHEs (Type 557a), the Heat Pumps (Type 927), the Heat Exchanger (Type 657), the Closed Circuit Cooling Tower (Type 510) and the circulation pumps.

The system is designed so as to cover the maximum cooling load during the net cooling period. Heat pumps and cooling tower cooling capacity are inputs which have been empirically selected so as to cover cooling demand with a safety coefficient of approximately $20 \%$. It is optimized using TRNOPT 17 [10]. A parametric analysis is performed considering as parameters: the hot-side outlet temperature set point of the Heat Exchanger, the Closed Circuit Cooling Tower working fluid flow rate and the desired outlet fluid temperature from the Closed Circuit Cooling Tower so as to minimize borehole depth. The parametric algorithm is performed, allowing parametric runs where one parameter at a time is varied and all others are fixed at their initial values. The parameters are assumed discrete and have a lower and upper limit.

Table 1 summarizes main parameters of the optimum HGSHPS at which the control strategies will be applied.

GHEs: In the current work 15 boreholes are used to exploit ground's cooling capacity. Type 557a models a set of equal vertical U-tube heat exchangers which thermally interact with the ground. Each one is placed in a separate borehole, filled with grout.
The boreholes are placed uniformly within a cylindrical storage volume of ground. There is convective heat transfer between the circulating fluid and the pipes and conductive heat transfer between the ground and the pipes. The depth below the surface of the top of GHEs determines the depth below the surface of the horizontal header pipe which is in conjunction with the GHEs. According to Hellström $[9,11]$, the temperature in the ground is determined by superposition of three terms: the global temperature, the local solution and the steady-

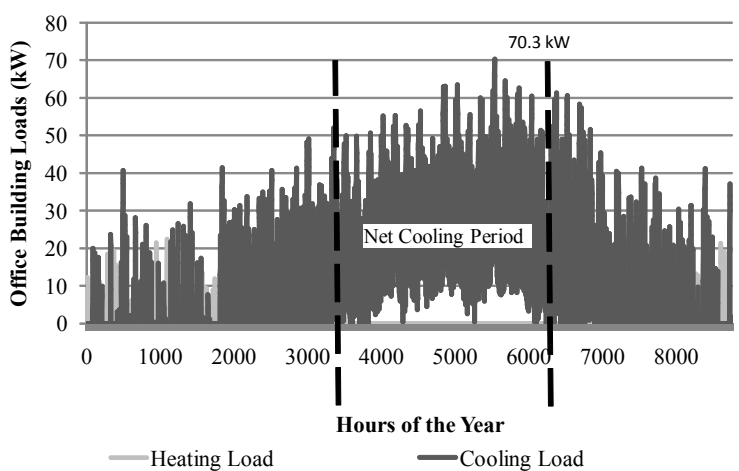

Figure 1: Annual building load profile.

\begin{tabular}{|c|c|}
\hline Parameter & Value \\
\hline Borehole number & 15 \\
\hline Borehole depth & $130 \mathrm{~m}$ \\
\hline Borehole separation & $4.5 \mathrm{~m}$ \\
\hline Borehole radius & $0.055 \mathrm{~m}$ \\
\hline Reference borehole flow rate & $1032 \mathrm{~kg} / \mathrm{h}$ \\
\hline U-tube inside diameter & $0.0218 \mathrm{~m}$ \\
\hline U-tube outside diameter & $0.0267 \mathrm{~m}$ \\
\hline Header depth & $1 \mathrm{~m}$ \\
\hline Storage volume & $34164 \mathrm{~m}^{3}$ \\
\hline Ground thermal conductivity & $2.42 \mathrm{~W} / \mathrm{m} \mathrm{K}$ \\
\hline Ground volumetric heat capacity & $2343 \mathrm{~kJ} / \mathrm{m}^{3} \mathrm{~K}$ \\
\hline Undisturbed ground temperature & $17^{\circ} \mathrm{C}$ \\
\hline Grout thermal conductivity & $1.5 \mathrm{~W} / \mathrm{m} \mathrm{K}$ \\
\hline Pipe thermal conductivity & $0.4 \mathrm{~W} / \mathrm{m} \mathrm{K}$ \\
\hline Source/Load fluid heat capacity & $4.19 \mathrm{~kJ} / \mathrm{kg} \mathrm{K}$ \\
\hline Source/Load Fluid density & $1000 \mathrm{~kg} / \mathrm{m}^{3}$ \\
\hline Load flow rate & $15480 \mathrm{~kg} / \mathrm{h}$ \\
\hline Rated cooling capacity per heat pump & $43 \mathrm{~kW}$ \\
\hline Rated cooling power per heat pump & $8.98 \mathrm{~kW}$ \\
\hline Rated source/load flow rate per heat pump & $4.3 \mathrm{l} / \mathrm{s}$ \\
\hline Overall circulation pumps efficiency & 0.6 \\
\hline Circulation pumps motor efficiency & 0.9 \\
\hline Effectiveness of heat exchanger & 0.65 \\
\hline Cooling tower design inlet fluid temperature & $35^{\circ} \mathrm{C}$ \\
\hline Cooling tower design outlet fluid temperature & $29.44^{\circ} \mathrm{C}$ \\
\hline Cooling tower design fluid flow rate & $7494 \mathrm{~kg} / \mathrm{h}$ \\
\hline Cooling tower design ambient air temperature & $35^{\circ} \mathrm{C}$ \\
\hline Cooling tower design wet bulb temperature & $25.56^{\circ} \mathrm{C}$ \\
\hline Cooling tower design air flow rate & $14334 \mathrm{~kg} / \mathrm{h}$ \\
\hline Cooling tower's air pressure at design conditions & $1 \mathrm{~atm}$ \\
\hline Cooling tower's rated fan power & $2.24 \mathrm{~kW}$ \\
\hline Number of simulation years & 15 \\
\hline
\end{tabular}

Table 1: Main parameters of the optimum HGSHPS at which the control strategies will be applied. 
Citation: Sagia Z, Rakopoulos C (2012) New Control Strategy for a Hybrid Ground Source Heat Pump System coupled to a Closed Circuit Cooling Tower. J Appl Mech Eng 1:108. doi:10.4172/2168-9873.1000108

flux solution. The global and local problems are solved with the use of an explicit finite difference method. The steady flux solution is obtained analytically.

As the undisturbed ground temperature is relatively high $17^{\circ} \mathrm{C}$, the circulating fluid through GHEs is water.

Heat pumps: Two equal single-stage water-to-water heat pumps are modelled through Type 927 [9]. In most time they work at partial load whereas bigger load coverage takes place at very hot summer days from the $5^{\text {th }}$ year until the $15^{\text {th }}$ so as to compromise for ground's cooling depletion. Heat pumps are dimensioned at $60 \%$ of the peak cooling load in an attempt to avoid repeatedly interruptions of their operation due to fluctuations of demand.

Input data files have been built for the normalized capacity and power draw, based on the entering load and source temperatures and the normalized source and load flow rates. These data have been derived from Water Furnace heat pumps catalog [12]

In addition two Excel data files are built. The first one provides Type 927 the inlet load temperature which is calculated by:

$$
T_{\text {load }, \text { out }}=T_{\text {load, in }}+\frac{\dot{Q}_{\text {cooling }}}{\dot{m}_{\text {load }} c_{p, \text { load }}} \Rightarrow T_{\text {load , in }}=T_{\text {load }, \text { out }}-\frac{\dot{Q}_{\text {cooling }}}{\dot{m}_{\text {load }} c_{p, \text { load }}}
$$

where $T_{\text {load }, \text { out }}=12^{\circ} \mathrm{C}, c_{p, \text { load }}=4.19 \mathrm{~kJ} / \mathrm{kgK}$ and $\dot{m}_{\text {load }}=\dot{m}_{\text {source }}$ for the current simulation.

Total cooling capacity $\dot{Q}_{\text {cooling }}$ is defined by:

$$
\dot{Q}_{\text {rejected }}=\dot{Q}_{\text {cooling }}+\dot{P}_{\text {cooling }}
$$

where $\dot{Q}_{\text {rejected }}$ is the heat rejected and $\dot{P}_{\text {cooling }}$ is the heat pump power.

$T_{\text {source out }}$ is given by:

$$
T_{\text {source,out }}=T_{\text {source, } \text { in }}+\frac{\dot{Q}_{\text {rejected }}}{\dot{m}_{\text {source }} c_{p, \text { source }}}
$$

The second one defines the control signal which indicates when the unit should be on or off in cooling mode. Assuming that the building is occupied 12 hours every day except Sundays, from 9 a.m. to 9 p.m., the control signal function for a whole week would be as it is plotted in Figure 3 , where 1 is on-signal and 0 is off-signal. It is useful to highlight that this signal is the operating signal of the whole HGSHPS and it has also been taken into consideration for the building load calculation.

Heat exchanger: Heat Exchanger is modelled by Type 657 [9] This type models a constant effectiveness heat exchanger which is able to automatically by-pass cold-side fluid around the heat exchanger in order to maintain the hot-side outlet temperature below a set point.

Closed circuit cooling tower: Type 510 [9] models a Closed Circuit Cooling Tower or in other words an indirect cooling tower or evaporator, based on Zweifel et al. [13] algorithm. This device is used to cool a liquid stream by evaporating water just outside of coils which contain the working fluid. The working fluid is completely isolated from air and water. In the current work the closed circuit cooling tower is operating at low speed (the fraction of rated fan speed does not exceeds 0.60) which leads to an oversized tower selection. Cooling tower's catalog data are derived from Baltimore Aircoil Company [14]

Circulation pumps: In this study there are three circulation pumps, each one per loop. In reality each pump represents a series of

\begin{tabular}{|c|c|c|c|c|}
\hline Month & $\begin{array}{l}\text { Ambient Air } \\
\text { Temperature, }{ }^{\circ} \mathrm{C}\end{array}$ & Mean irradiance of global radiation horizontal, $\mathrm{W} / \mathrm{m}^{2}$ & Mean irradiance of diffuse radiation horizontal, W/m² & $\begin{array}{l}\text { Wet Bulb } \\
\text { Temperature, }{ }^{\circ} \mathrm{C}\end{array}$ \\
\hline JUN & 25.6 & 297 & 105 & 17.5 \\
\hline JUL & 28.4 & 299 & 98 & 19.4 \\
\hline AUG & 28.0 & 271 & 90 & 19.3 \\
\hline SEP & 23.5 & 216 & 80 & 17.1 \\
\hline
\end{tabular}

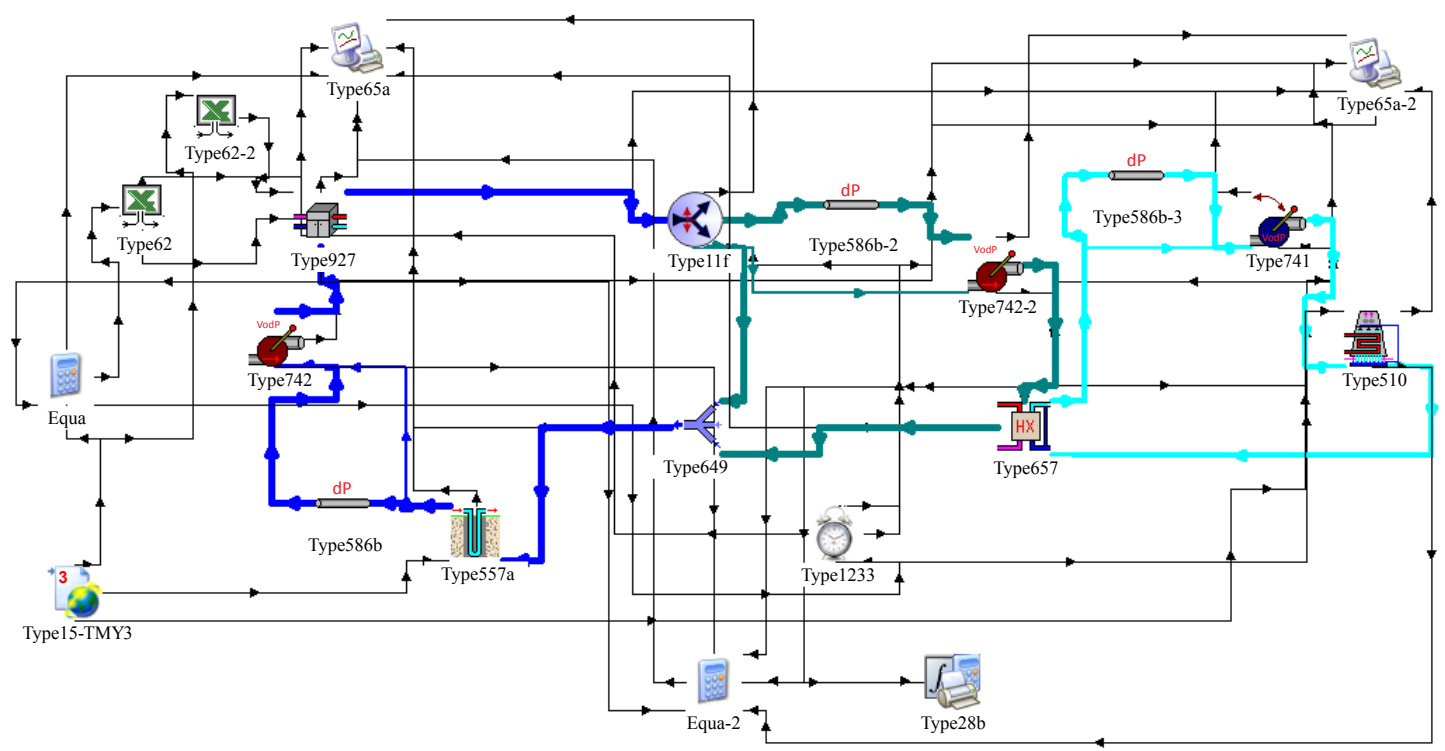

Figure 2: HGSHPS TRNSYS 17 Modelling.

Table 2: Average Climatic data [6]. 
pumps which should be placed in an actual installation. The amount of water flowing through each pump equates to the amount of water that should flow through the series of pumps of each loop.

Type 742 [9] models a pump which sets its fluid outlet mass flow rate equal to desired inlet mass flow rate. It can model a constant or a variable speed pump by passing the inlet mass flow rate through to its output but, does not take any control signal. The pump's power draw is calculated from the pressure drop, overall pump efficiency, motor efficiency, fluid flow rate and fluid characteristics. Pump's starting and stopping characteristics are not modelled.

Type 586b [9] calculates the input pressure drop for circulation pumps' calculations. As this case study is not referred to an actual installation but, to a possibly existing one the estimation of piping length is difficult. Based on [5] methodology for piping length estimation, the piping network of GHEs' loop is assumed to be 856.5 $\mathrm{m}$, of Heat Exchanger loop $20 \mathrm{~m}$ and of Closed Circuit Cooling Tower loop $20 \mathrm{~m}$.

Type 741 [9] models a variable speed pump that is able to produce any mass flow rate between zero and its rated flow rate. The pump's power draw is calculated similarly to Type 742 . The reason for which this type is chosen for modelling the circulation pump of Closed Circuit Cooling Tower loop instead of Type 742 is its ability to modify the outlet flow rate based on its rated flow rate parameter and the current value of its control signal input.

\section{Control Strategies}

Control strategies utilized in the present work define when the

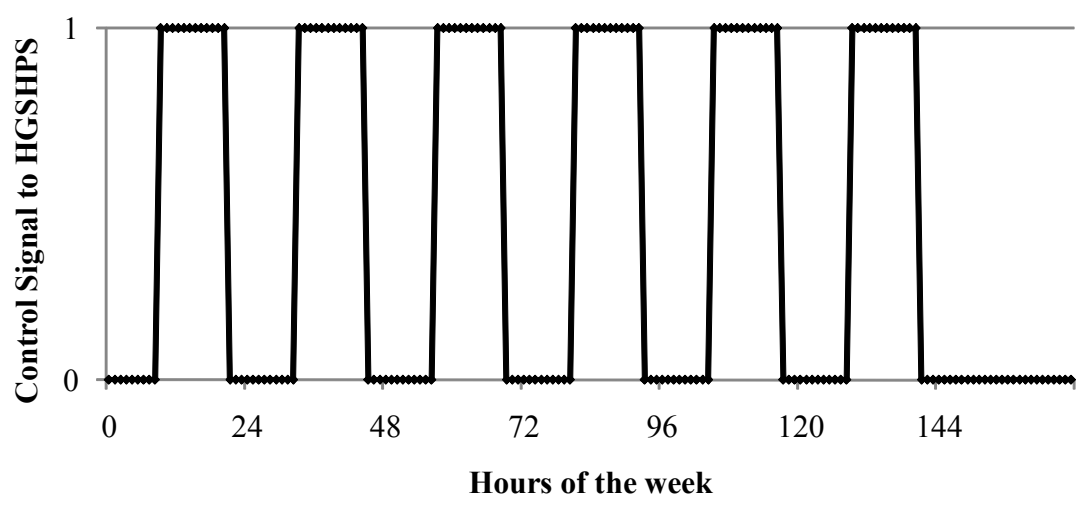

Figure 3: Weekly Control Signal to HGSHPS.

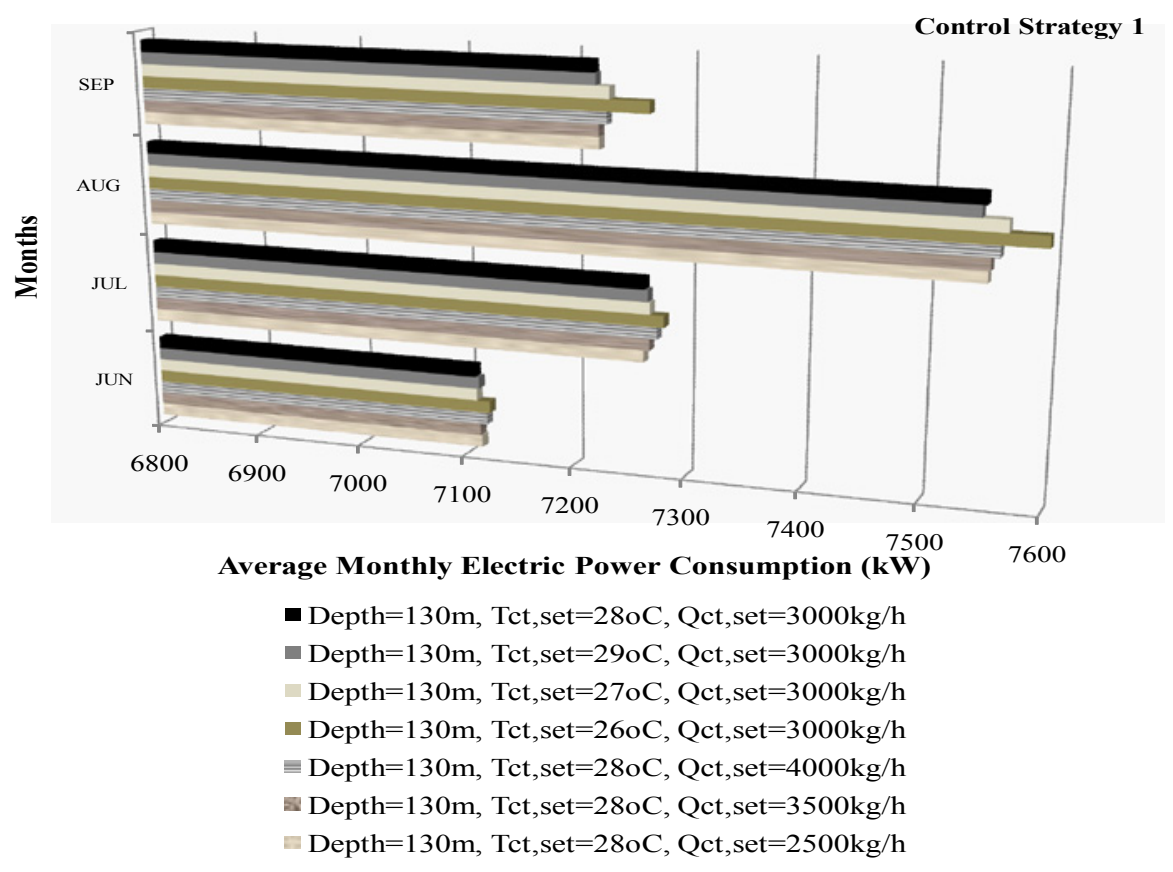

Figure 4: Average monthly electric power consumption for Control Strategy 1. 
Citation: Sagia Z, Rakopoulos C (2012) New Control Strategy for a Hybrid Ground Source Heat Pump System coupled to a Closed Circuit Cooling Tower. J Appl Mech Eng 1:108. doi:10.4172/2168-9873.1000108

Closed Circuit Cooling Tower should be turned on or off. Three different control strategies are examined so as to minimize HGSHPS's electric power consumption. Type 1233 is utilized so as to send the appropriate control signal to fluid diverter (Type 11f) and to circulation pump Type 741. The system's electric power consumption is the sum of five terms: heat pump power, power of each circulation pump (three values of power for the current simulation, each one per loop) and cooling tower fan power.

Apart from the control strategies two other control functions are used to ensure the temperature and flow rate control in the studied HGSHPS. The first one is the hot-side outlet temperature set point of the Heat Exchanger which is:

$$
T_{H E X, s e t}=38^{\circ} \mathrm{C}
$$

The second one is the desired outlet fluid temperature which the Closed Circuit Cooling Tower tries to maintain and is:

$$
T_{C T, \text { set }}=28^{\circ} \mathrm{C}
$$

\section{Control strategy 1}

Control strategy 1 suggests that the cooling tower should operate when the temperature difference between the fluid temperature exiting heat pumps and ambient air wet bulb temperature exceeds a given set point:

$$
\Delta T_{1}=T_{\text {source,out }}-T_{\text {wetbulb }}>10^{\circ} \mathrm{C}
$$

In an attempt to define the climatic area for which the HGSHPS is designed, Athens monthly average climatic data are presented in Table 2 .

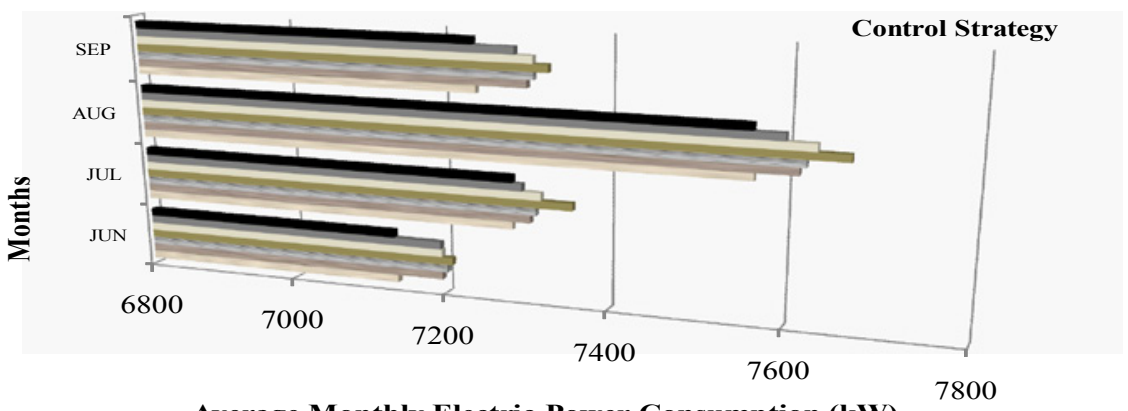

Average Monthly Electric Power Consumption (kW)

- Depth $=130 \mathrm{~m}$, Tct, set $=280 \mathrm{C}$, Qct, set $=3000 \mathrm{~kg} / \mathrm{h}$

Depth $=130 \mathrm{~m}$, Tct, set $=290 \mathrm{C}$, Qct, set $=3000 \mathrm{~kg} / \mathrm{h}$

Depth $=130 \mathrm{~m}$, Tct, set $=27 \mathrm{oC}, \mathrm{Qct}, \mathrm{set}=3000 \mathrm{~kg} / \mathrm{h}$

Depth $=130 \mathrm{~m}$, Tct, set $=260 \mathrm{C}, \mathrm{Qct}, \mathrm{set}=3000 \mathrm{~kg} / \mathrm{h}$

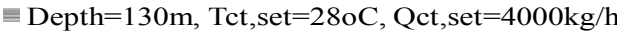

a Depth $=130 \mathrm{~m}, \mathrm{Tct}, \mathrm{set}=28 \mathrm{oC}, \mathrm{Qct}, \mathrm{set}=3500 \mathrm{~kg} / \mathrm{h}$

Inepth $=130 \mathrm{~m}$, Tct, set $=28 \mathrm{oC}, \mathrm{Qct}, \mathrm{set}=2500 \mathrm{~kg} / \mathrm{h}$

Figure 5: Average monthly electric power consumption for Control Strategy 2.

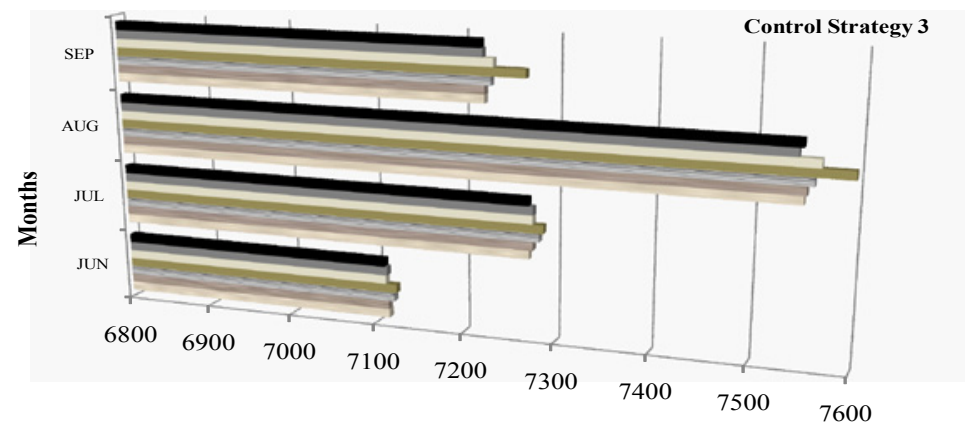

Average Monthly Electric Power Consumption (kW)

- Depth=130m, Tct,set=28oC, Qct,set=3000kg/h

Depth $=130 \mathrm{~m}$, Tct,set $=290 \mathrm{C}, \mathrm{Qct}, \mathrm{set}=3000 \mathrm{~kg} / \mathrm{h}$

Depth $=130 \mathrm{~m}$, Tct,set $=27 \mathrm{oC}, \mathrm{Qct}, \mathrm{set}=3000 \mathrm{~kg} / \mathrm{h}$

Depth $=130 \mathrm{~m}$, Tct,set $=260 \mathrm{C}, \mathrm{Qct}, \mathrm{set}=3000 \mathrm{~kg} / \mathrm{h}$

$=\mathrm{Depth}=130 \mathrm{~m}, \mathrm{Tct}, \mathrm{set}=28 \mathrm{oC}, \mathrm{Qct}, \mathrm{set}=4000 \mathrm{~kg} / \mathrm{h}$

इ Depth $=130 \mathrm{~m}$, Tct, $\mathrm{set}=28 \mathrm{oC}, \mathrm{Qct}, \mathrm{set}=3500 \mathrm{~kg} / \mathrm{h}$

Depth $=130 \mathrm{~m}, \mathrm{Tct}, \mathrm{set}=28 \mathrm{oC}, \mathrm{Qct}, \mathrm{set}=2500 \mathrm{~kg} / \mathrm{h}$

Figure 6: Average monthly electric power consumption for Control Strategy 3. 


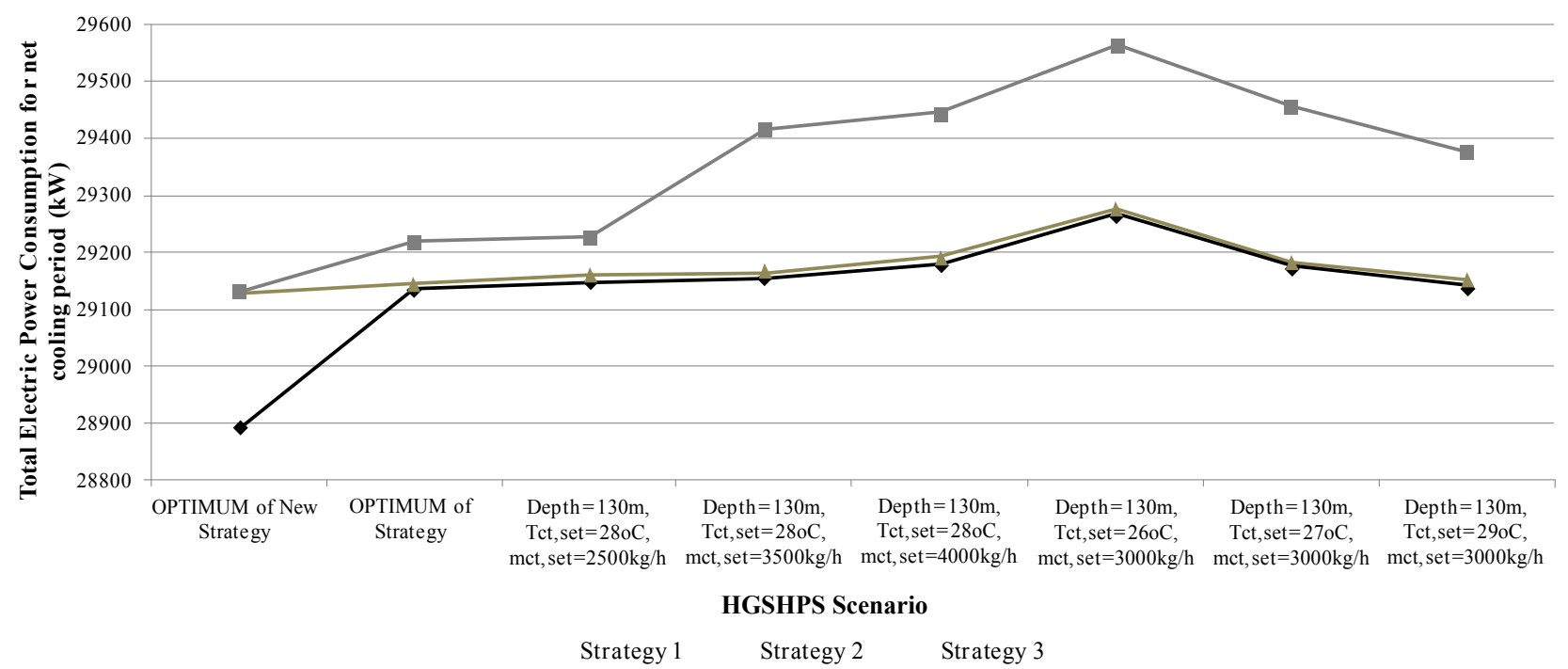

Figure 7: Total electric power consumption for net cooling period.

\section{Control strategy 2}

Control Strategy 2 activates the cooling tower when the fluid temperature exiting GHEs is greater than a certain value:

$$
T_{G H E, \text { out }}>28^{\circ} \mathrm{C} \text {. }
$$

\section{Control strategy 3}

Control Strategy 3 sets cooling tower on when the fluid temperature exiting heat pumps is greater than a given value:

$$
T_{\text {source,out }}>32^{\circ} \mathrm{C}
$$

\section{New control strategies}

Each of the control set points discussed above is normalized by the fluid temperature exiting the hot side of heat exchanger, $T_{H E X, \text { hot, out }}$. New set points are calculated which define three new control strategies. Equations (6) to (8) are transformed into:

$$
\begin{aligned}
& \frac{\Delta T_{1}}{T_{H E X, \text { hot, out }}}=\frac{T_{\text {source, out }}-T_{\text {wetbulb }}}{T_{H E X, \text { hot }, \text { out }}}>0.3 \\
& \frac{T_{G H E, \text { out }}}{T_{H E X, \text { hot out }}}>1.3 \\
& \frac{T_{\text {source, out }}}{T_{H E X, \text { hot }, \text { out }}}>1.3
\end{aligned}
$$

and define three new control strategies 1, 2, 3 respectively.

\section{Results}

Moving to the results section, the average monthly electric power consumption for Control Strategies 1, 2, 3 is presented in figures 4, 5, 6 respectively. For the optimum borehole depth of $130 \mathrm{~m}$, different desired outlet fluid temperature $T_{C T, \text { set }}$ and cooling tower set point flow rates $\dot{m}_{C T, \text { set }}$ are examined. In all Control Strategies the first scenario, the black one, that is $T_{C T, \text { set }}=28^{\circ} \mathrm{C}$ and $\dot{m}_{C T, \text { set }}=3000 \mathrm{~kg} / \mathrm{h}$ accounts for the smallest overall electric power consumption. However, in August the second scenario, the dark grey one, that is $T_{C T, \text { set }}=29^{\circ} \mathrm{C}$ and
$\dot{m}_{C T, \text { set }}=3000 \mathrm{~kg} / \mathrm{h}$ leads to the smallest electric power consumption for Control Strategies 1 and 3.

Control Strategies 1 and 3 have similar results, with Control Strategy 1 to account for the smallest electric power consumption in all scenarios. To validate this remark, it should be mentioned that previous works $[3,15]$ which have examined the same scenario among others, into different HGSHPSs have reached to the same conclusion. This conclusion becomes more obvious in figure 7 where the total electric power consumption for one-year net cooling period is plotted. The $\mathrm{x}$-axis coordinate 'OPTIMUM of Strategy' is referred to scenario that is borehole depth $=130 \mathrm{~m}, T_{C T, \text { set }}=28^{\circ} \mathrm{C}$ and $\dot{m}_{C T, \text { set }}=3000 \mathrm{~kg} / \mathrm{h}$ and 'OPTIMUM of New Strategy' is referred to the same scenario at which the New Control Strategies are applied. It is worth saying that New Control Strategyl accounts by far for the least electric power consumption which is approximately $28895 \mathrm{~kW}$. All New Control Strategies lead to better results that is to say less demand for electric power in comparison with the optimum of each strategy. The optimum of new strategies 2 and 3 is $29127 \mathrm{~kW}$ and $29130 \mathrm{~kW}$ respectively. These values are very close but still smaller than the optimum of Control Strategy 1 which is $29137 \mathrm{~kW}$. It should be noted that the range of examined values for the electric power consumption is small and that is an expected remark as they referred to a previous optimized system.

However, as certain critical parameters such as heat pumps' and cooling tower cooling capacity have not been considered in the optimization procedure as variables, the optimization may be considered as restricted under the studied conditions. Despite the fact of the above mentioned assumptions, the results indicate the optimum control policy for the cooling tower operation in the HGSHPS and can provide useful guidance to future attempts for solving this complex sizing problem.

Figure 8 shows the distribution of total electric power consumption in the 'optimum' HGSHPS which is regulated by new control strategy 1 and control strategy 1 for the net cooling period. In both pie-diagrams of figure 8 , the biggest power consumption derives from the heat pumps and then with declining order from the circulation pump of GHEs' loop, cooling tower fan, circulation pump of Closed Circuit 
Total Electric Power Consumption of HGSHPS controlled by Strategy 1, for one-year Net Cooling Period

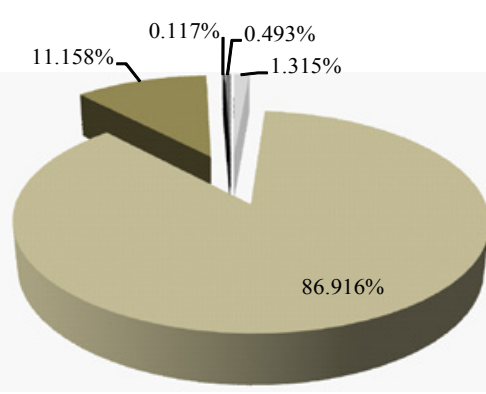

Fan Power of Closed Circuit Cooling Tower

$\square$ Heat Pumps' Power

- Circulation Pump Power of GHEs' loop

- Circulation Pump Powe of Heat Exchanger loop

n Circulation Pump Power of Closed Circuit Cooling Tower

(a)

Total Electric Power Consumption of HGSHPS controlled by New Strategy 1, for one-year Net Cooling Period

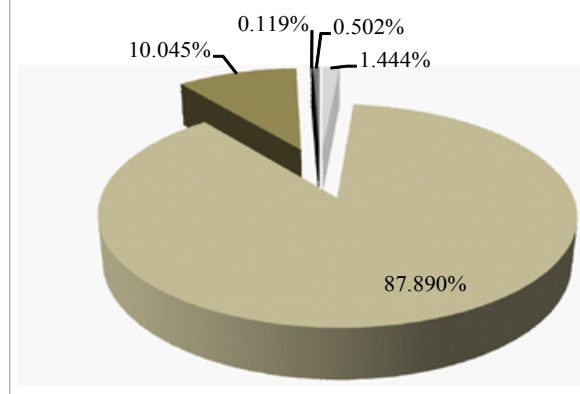

Fan Power of Closed Circuit Cooling Tower

Heat Pumps' Power

- Circulation Pump Power of GHEs' loop

- Circulation Pump Power of Heat Exchanger loop

Circulation Pump Power of Closed Circuit Cooling Tower

Figure 8: Distribution of total electric power consumption of HGSHPS for one-year net cooling period controlled by: a) Strategy 1 b) New Strategy 1.

Cooling Tower loop and circulation pump of Heat Exchanger loop. The relatively small increase in heat pumps' and fan power consumption in comparison with the relevant decrease in total circulation pumps' power is indicative of the improvement to fluid circulation.

Figure 9 is plotted in an attempt to visualize the conditions at which the optimum HGSHPS of our study operates. System's parameters are borehole depth $=130 \mathrm{~m}, T_{C T, \text { set }}=28^{\circ} \mathrm{C}$ and $\dot{m}_{C T, \text { set }}=3000 \mathrm{~kg} / \mathrm{h}$ as it has been mentioned above and Closed Circuit Cooling Tower operation is regulated by new control strategy 1 . Distribution of inlet and outlet temperatures of load and source side of heat pumps, of GHEs, of Heat Exchanger and Closed Circuit Cooling Tower is presented for a very hot, cooling week in August. Inlet GHEs temperature is smaller than outlet source heat pumps temperature but still significant high in comparison with Heat Exchanger outlet temperature due to by-pass flow. The temperature difference between the fluid entering and exiting GHEs is $2^{\circ} \mathrm{C}$ greater than the temperature difference of heat pump's load side. The temperature difference between the fluid entering and exiting Closed Circuit Cooling Tower is on average $6.5^{\circ} \mathrm{C}$, while the outlet hot-side temperature of Heat Exchanger during the last working days do not succeed to maintain below the set point of $38^{\circ} \mathrm{C}$.

\section{Conclusion}

To conclude, in the current work different control policies for HGSHPS optimization during the net cooling period have been applied to a Greek office building. The optimization is focused on the minimization of electric power consumption assuming certain values for the building load, the heat pumps' and cooling tower maximum cooling capacity. Therefore, it might not be considered as a full system optimization but it still could be considered as a determining improvement in system's operation.

By minimizing the electric power consumption, a significant reduction to HGSHPS operating cost should be achieved. However, it is difficult to claim that this is the most economically beneficial scenario, not only because the heating period is not examined but, also because the investment and maintain cost have not been considered in unit selection.

New control strategy 1 is the best of the examined so as to regulate Closed Circuit Cooling Tower's operation in the HGSHPS. All new control strategies achieve a better regulation to system operation which leads to an extra reduction in the electric power consumption. These remarks can be used as guidance to future HGSHPS designers.

\section{Nomenclature}

$\begin{array}{ll}c_{p} & \text { Specific heat capacity, } \mathrm{kJ} /(\mathrm{kg} \mathrm{K}) \\ g . & \text { Solar heat gain coefficient } \\ \ddot{P}_{\text {cooling }} & \text { Mass flow rate, } \mathrm{kg} / \mathrm{h} \\ \dot{Q}_{\text {cooling }} & \text { Heat pump power, } \mathrm{kW} \\ \dot{Q}_{\text {rejected }} & \text { Heat pump cooling capacity, } \mathrm{kW} \\ T & \text { Heat rejected by heat pump, } \mathrm{kW} \\ u & \text { Temperature, }{ }^{\circ} \mathrm{C} \\ u & \text { Thermal transmittance, } \mathrm{W} /\left(\mathrm{m}^{2} \mathrm{~K}\right)\end{array}$

Subscripts and superscripts used in various formulas throughout the text

$\begin{array}{ll}\text { CT } & \text { Cooling Tower } \\ \text { GHE } & \text { Ground Heat Exchanger } \\ \text { HEX } & \text { Heat Exchanger } \\ \text { in/out } & \text { Inlet/Outlet } \\ \text { load/source } & \text { Heat Pump load-side/source-side } \\ \text { set } & \text { Set point } \\ \text { wetbulb } & \text { Wet bulb }\end{array}$

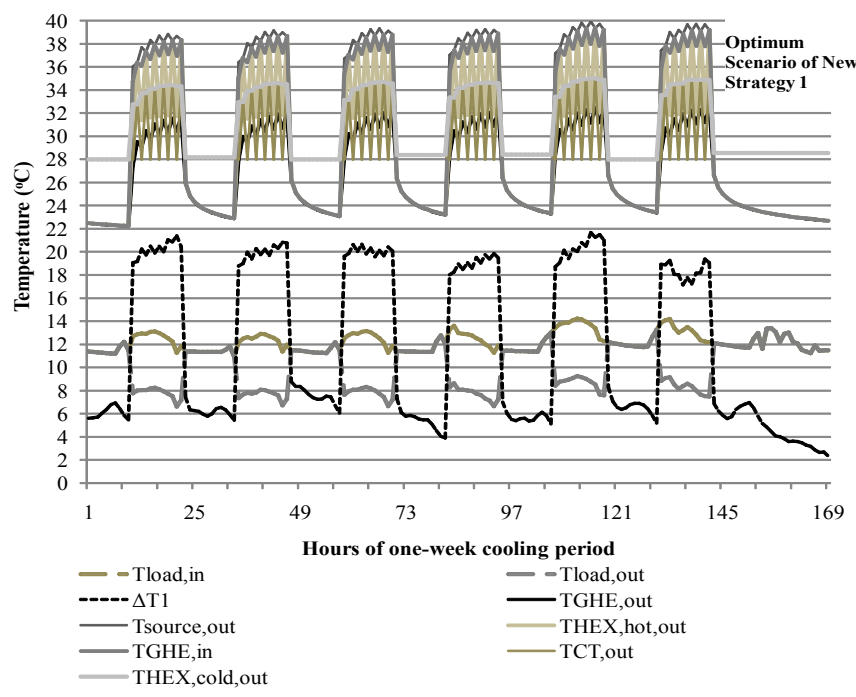

Figure 9: Temperature distribution in HGSHPS controlled by New Strategy 1 for one-week cooling period in August. 
Citation: Sagia Z, Rakopoulos C (2012) New Control Strategy for a Hybrid Ground Source Heat Pump System coupled to a Closed Circuit Cooling Tower. J Appl Mech Eng 1:108. doi:10.4172/2168-9873.1000108

Page 8 of 8

\section{References}

1. Kavanaugh SP (1998) A design method for hybrid ground-source heat pumps. ASHRAE Transactions 104: 691-698.

2. ASHRAE (1995) Commercial/institutional ground-source heat pumps engineering manual. American Society of Heating, Refrigerating and AirConditioning Engineers: Caneta Research, Inc., Atlanta.

3. Yavuzturk C, Spitler JD (2000) Comparative Study of Operating and Contro Strategies for Hybrid Ground-Source Heat Pump Systems Using a Short Time Step Simulation Model. ASHRAE Transactions 106: 192-209.

4. Xu X (2007) Simulation and optimal control of hybrid ground source heat pump systems, Oklahoma, United States of America: Oklahoma State University.

5. Hackel SP (2008) Development of Design Guidelines for Hybrid GroundCoupled Heat Pump Systems. ASHRAE TRP-1384.

6. Meteonorm Software 2010; v.6.1.

7. Technical Chamber of Greece, Comprehensive national standards parameters for calculating the energy performance of buildings and issuing of energy performance certificate. Technical Instruction 20701-1/2010; 2010. Building PECA Minister Decision 17178/2010. Official Gazette 1387/B/9-2-2010.

8. TRNSYS Software 2010; v.17.

9. TESS Library 2010.

10. TRNOPT $17 ; 2010$.

11. Hellström G (1989) Duct ground heat storage model. Lund, Sweden: University of Lund, Department of Mathematical Physics. Manual for Computer Code.

12. Water Furnace website

13. Zweifel G, Dorer V, Koschenz M, Weber A (1995) Building Energy and System Simulation Programs: Model Development, Coupling and Integration. Proceedings of International Building Performance Simulation Association Conference.

14. Baltimore Aircoil Company website.

15. Thermal Energy Systems Specialists (2005) Hybrid Geothermal Heat Pumps a Fort Polk, Louisiana. Final Report to Oak Ridge National Laboratory. 